Corrigendum

\title{
Corrigendum to "Automated Feature Extraction in Brain Tumor by Magnetic Resonance Imaging Using Gaussian Mixture Models"
}

\author{
Ahmad Chaddad, ${ }^{1}$ Markus Luedi, ${ }^{1}$ Pascal O. Zinn, ${ }^{2}$ and Rivka Colen ${ }^{1}$ \\ ${ }^{1}$ Department of Diagnostic Radiology, University of Texas MD Anderson Cancer Center, 1400 Pressler Street, Houston, TX 77030, USA \\ ${ }^{2}$ Baylor College of Medicine, 1 Baylor Plaza, Houston, TX 77030, USA \\ Correspondence should be addressed to Ahmad Chaddad; ahmad.chaddad@univ-lorraine.fr \\ Received 10 April 2017; Accepted 19 April 2017; Published 13 August 2017 \\ Copyright (c) 2017 Ahmad Chaddad et al. This is an open access article distributed under the Creative Commons Attribution \\ License, which permits unrestricted use, distribution, and reproduction in any medium, provided the original work is properly \\ cited.
}

\begin{abstract}
In the article titled "Automated Feature Extraction in Brain Tumor by Magnetic Resonance Imaging Using Gaussian Mixture Models" [1], Markus Luedi, Pascal Zinn, and Rivka Colen were missing from the authors' list. The corrected authors' list is shown above.
\end{abstract}

\section{References}

[1] A. Chaddad, "Automated feature extraction in brain tumor by magnetic resonance imaging using gaussian mixture models," International Journal of Biomedical Imaging, vol. 2015, Article ID 868031, 11 pages, 2015. 


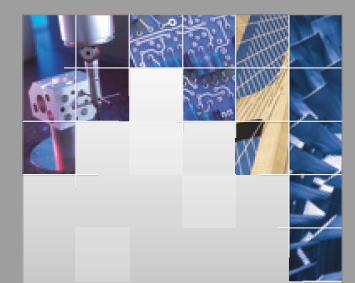

\section{Enfincering}
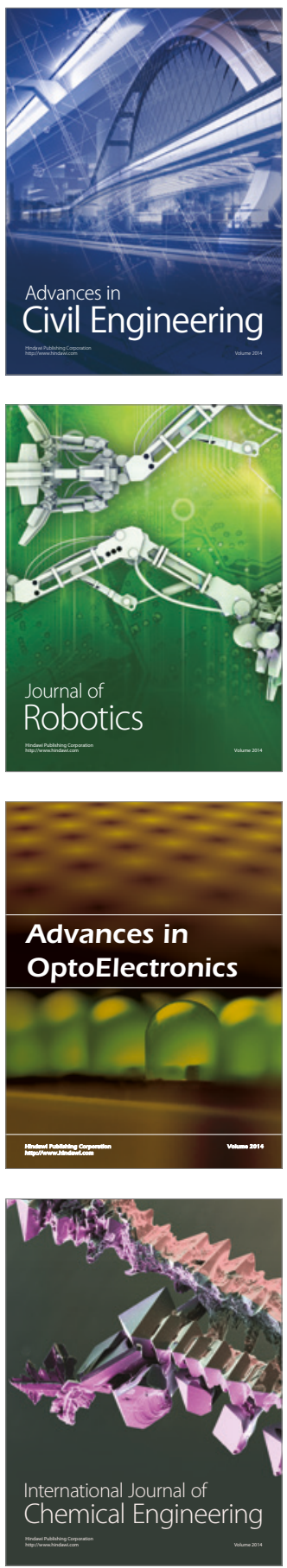

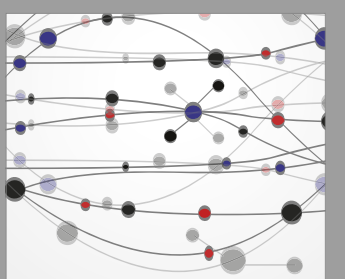

The Scientific World Journal

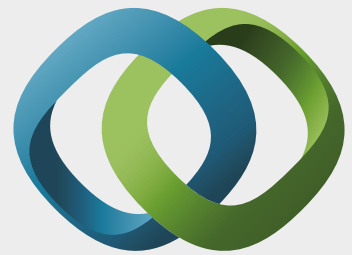

\section{Hindawi}

Submit your manuscripts at

https://www.hindawi.com
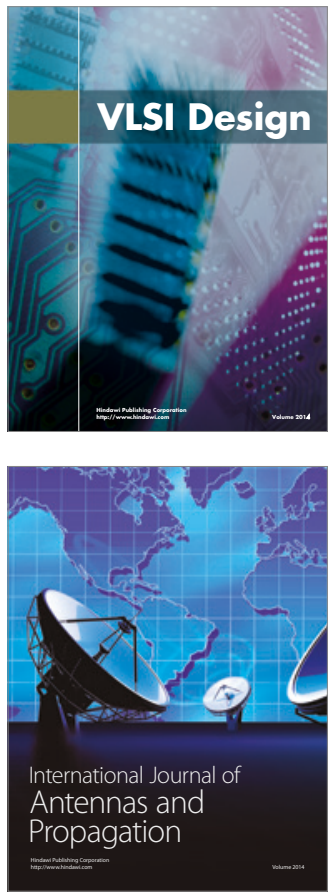

\section{Rotating}

Machinery
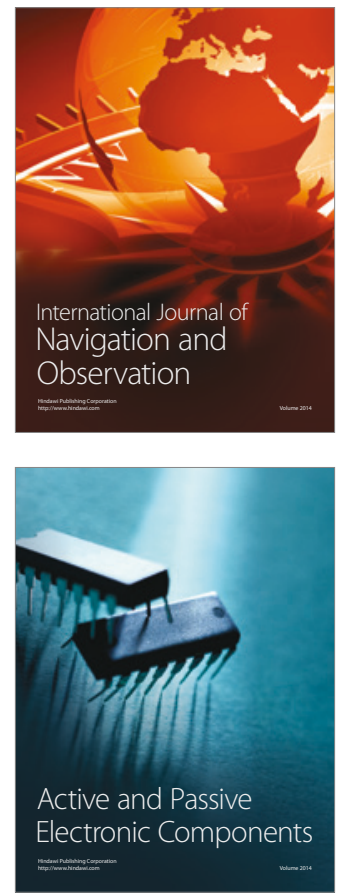
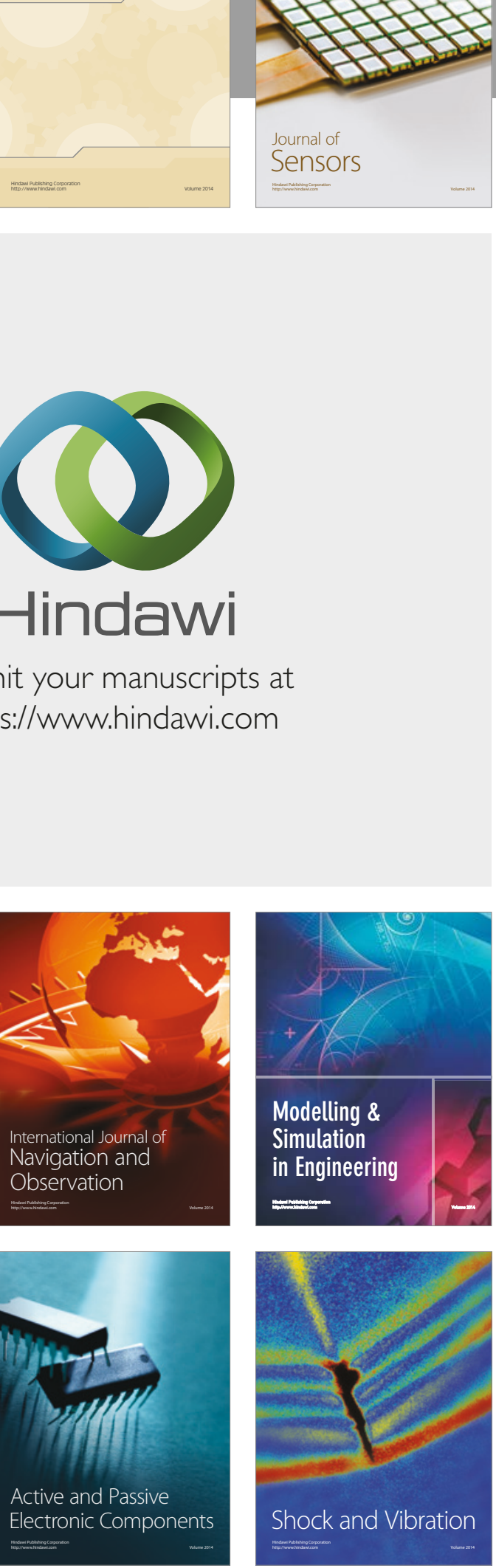
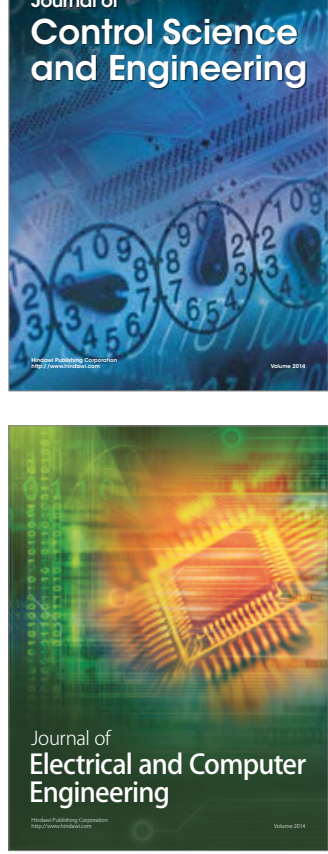

Distributed

Journal of

Control Science

and Engineering
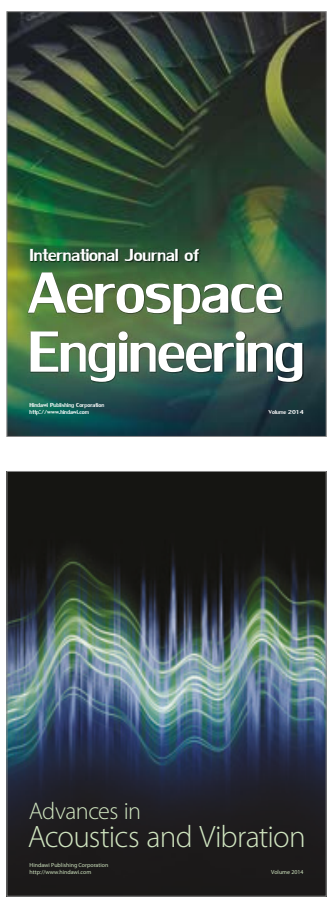

Sensor Networks 